\title{
USP: as curvas da modernidade
}

\author{
EDUARDO PORTELLA
}

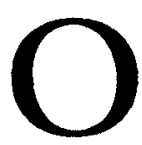

s primeiros anos trinta, mesmo quando confrontam e contradizem a Revolução que os determina, estão marcados por uma decisão radical de mudança. A idéia que animou a criaçáo da Universidade de Sáo Paulo irrompe nesse quadro de transformaçóes, sem disfarçar a sua predominante ascendência francófila, ilustrada, secular, liberal, sobre a qual o mínimo que se deve dizer é que foi oportuna e conseqüente.

A efervescência cultural precede, como costuma acontecer, às edificacóes acadêmicas. O Modernismo sulista e o Regionalismo nordestino são responsáveis diretos, através de suas diferentes manifestações, pela vontade instauradora que se dissemina nos quatro cantos do país. Os fundadores da USP e da UDF representam, com idêntico vigor, esse compromisso transformador. Caso contrário não teríamos hoje, diante do nosso olhar pretensiosamente avaliador, esse conjunto de realizaçóes tão convincente. Uma Universidade é sempre a sua capacidade de transformar e de se transformar.

O projeto USP nasce sob o signo das bumanidades, mas numa concepçăo larga, cuja primeira inscrição, logo à entrada do Decreto que a institui, programa: "a) promover, pela pesquisa, o progresso da ciência." E, em seguida, se acrescenta: "b) transmitir, pelo ensino, conhecimentos que enriqueçam ou desenvolvam o espírito ou sejam úteis à vida; c) formar especialistas em todos os ramos de cultura e técnicos e profissionais em todas as profissóes de base científica ou artística; d) realizar a obra social de vulgarização das ciências, das letras e das artes, por meio de cursos sintéticos, conferências, palestras, difusão pelo rádio, filmes científicos e congêneres.

O caráter integrador se destaca desde esses primeiros dias, dissolvendo ou reencaminhando as dificuldades políticas persistentes. É um dos raros momentos de encontro do saber com o poder, numa síntese aberta em que se entendem, emblematicamente, Julio de Mesquita Filho e Paulo Duarte; e na qual Armando de Salles Oliveira comparece como a instância viabilizadora. O Estado de Sáo Paulo compreende, pioneiramente, a importância dos investimentos educacionais como fator de 
qualificação do desenvolvimento econômico, o conhecimento como fonte de liberdade.

\section{Atualidade das origens}

Pode parecer um certo exagero historicista, ou simplesmente historiográfico, afirmar-se que a cinquientenária Universidade de São Paulo tanto mais se afirma quanto mais se mantém fiel às suas origens. Quando delas se afasta, seduzida por filosofemas extremistas, projeta uma imagem pouco flexível, inesperadamente maniqueísta. O saber aqui já não é capaz de ver a realidade: apenas consome as suas representacóes ideológicas. $\mathrm{E}$ isto acontece toda vez que o autoritarismo, instalado à direita ou à esquerda, impóe o mito falacioso da revoluçáo. Os processos ideológicos - os métodos também - se mostraram incapazes de superar as contradiçóes. Sobretudo quando elas rebentam o cimento infraestrutural.

É absurdo precipitar-se a conclusão, às vezes decorrente, de que a Universidade não deva ser um projeto político. Foi como projeto político destinado a formar uma elite nacional, conforme o melhor receituário iluminista, que a conceberam os fundadores da USP. Compreende-se, hoje mais claramente, depois de tantas ilusóes perdidas, a recusa antecipadora da escola apenas profissionalizante. Mais do que tudo, convém registrar o destaque conferido à Faculdade de Filosofia, Ciências e Letras - à Faculdade de Filosofia enquanto a cabeça da Universidade.

Nestes tempos táo deceptados quanto decepcionados, em que velhas guilhotinas ideológicas continuam dedicando-se a suas tarefas habituais, é preciso voltar a pensar. E não será por meio da técnica, extraviada na tecnocracia, que recuperaremos esse lugar demarcado, com tanto rigor, pelos pioneiros da USP. Pelo contrário: é justamente a filosofia que poderá redirecionar o vôo cego da técnica. A vida da Universidade como Universidade da vida não perde por esperar esse reencontro.

Enquanto ele se retarda, a Universidade brasileira - a USP não escapa a essa regra geral - limita-se a recolher de volta, diariamente, o mesmo rosto com que contempla a crise nacional. É um círculo vicioso de difícil superação. Até porque, se as suas propostas mais dinâmicas, mais condizentes com os seus fins, deparam-se a todo instante com obstáculos quase intransponíveis, a política de meios que a circunda e domina permanece subordinada a um centro de decisáo nunca verdadeiramente universitário. São contingências que se agravam, em meio à voracidade do expansionismo tecnocrático. $\mathrm{E}$ aí a Universidade se impacienta porque se reconhece como um espaço ameaçado ou condenado, 
que perdeu de uma só vez a legitimidade e a força legitimadora. O percurso inverso, a possível saída para o impasse, corresponderá à desincompatibilização de conbecimento e interesse. Não me parece que a USP de hoje, ainda dispersa por pequenas escaramuças ideológicas, esteja a caminho desse reencontro. A tecnocracia e o seu oposto, ou melhor, as tecnocracias, herdeiras diletas do triunfalismo, jamais vacilam em gritar, com os plenos pulmóes da certeza, o perigo da dúvida. Como se não fosse ela, a instabilidade, $e$ até a insegurança, o oxigênio da reflexão contemporânea, ao longo do trajeto sinuoso da modernidade.

Os fundadores da USP puderam falar nos chamados altos estudos desinteressados. Nós já não temos esse direito. Da Universidade, de suas açōes-argumentativas, terá de sair o antídoto do Estado tecnocrático. E neste sentido, em que pesem iniciativas isoladas, ou esforços individuais, a Universidade meio-centenária reproduz, numa trajetória em que se alternam a opulência e a pauperizaçáo, a crise do poder recessivo instalado no país. A Universidade renuncia à sua condiçáo de ponte entre a Cultura e a Educação, porque não consegue ou não pretende transpor as limitaçóes do saber apenas instrumental.

O tecnocratismo, em vez de reprogramar, destrói as raízes liberais. O mandarinato acadêmico, obediente e zeloso, astuciosamente zeloso e obediente, investiu na formação de quadros táo fechadamente burocráticos quanto socialmente desfibrados. O gigantismo gerencial inibiu ou bloqueou chances de vida nova. A perplexidade dos setores virtuosistas se entregou, com alguma frequiência, à tagarelice dos discursos nostálgicos ou simplesmente memorialistas. Tentou legitimar, pela via exclusiva, e em alguns casos excludente, da tradição, em projeto cada vez mais necessitado de prospecção crítica. As boas intençōes desse comportamento, todo vazado naquele humanismo que venho chamando de filantrópico, náo dispunham de resistências mais sólidas para oporem à avalanche tecnocrática.

\section{A agenda rasurada}

O sonho liberal dos primeiros anos $\mathbf{3 0}$ sofre aqui os seus mais duros golpes. A agenda cuidadosamente elaborada pelos pioneiros se vê abruptamente rasurada pelo poder perverso, que se reflete na Universidade atoinstitucionalizada. O tecnocratismo, sócio do mando insular, ilhou ainda mais a Universidade. $O$ fosso que se interpós entre o trabalho acadêmico e a vida social assumiu proporçóes insuportáveis - $\mathrm{em}$ detrimento de ambos. A sociedade ignora a Universidade que a ignora. Com a orgia instrumental, a Universidade se nega enquanto motor do avanço social. O próprio desempenho pacifista, conquista do diálogo, fica comprometido. O saber prático só sabe praticar violência. 
É quando a ciência econômica, aqui oca de sociabilidade e de subjetividade, aperfeiçoa os seus arsenais explicativos. Evidentemente uma justificativa monocórdia, um delírio monotemático, desdobrados sob os auspícios da econometria mais monetarista. $O$ tema eleito por toda essa montagem explicativa foi a inflaçáo. Um tema que, ao que tudo indica, não se dá bem com o fanatismo exegético. Quanto mais se vê explicada, tanto mais cresce.

A USP, mesmo levando em consideraçáo a inigualável força de sua produtividade intelectual, terá sempre, daqui por diante, de se justificar perante a naçáo por haver fornecido a cobertura explicativa, com o correspondente sotaque autoritário, para a ditadura econômica que nos corrói por dentro e por fora.

Não tem sido possivel, à Universidade de São Paulo, desenvolver o modelo talvez misto - solidamente ancorado no porto seguro da filosofia, das ciências e das letras -, que se delineou naquelas horas matinais. A proscriçăo e obstruçăo ceifaram ou desestimularam cabeças que se fortaleceriam nestas duas décadas. Diversificadamente. Mesmo porque um país é também o elenco de temas de que dispóe. E nós ficamos reduzidos a um tema obsessivo-compulsivo, naturalmente cercado pelos seus correlatos: a inflaçăo. Sob a sua égide se cometem aberraçóes, porém sem desviar-se do rumo mitigado do capitalismo tardio no Brasil recessivo. Quem sabe se a USP das bumanidades, que por razóes óbvias É a que acompanho mais de perto, não poderá abrir frestas inadiáveis nesse nevoeiro tecnocrático? Ou até recambiar o barco extraviado? A contribuiçáo da USP para o ensino de Letras, por exemplo, é fundamental para todo o país.

Os álibis de que se serve a impostura tecnocrática giram em torno das promessas de modernização. Mas a modernização é decorrência da democracia. A argúcia crítica de Octavio Paz, reafirmada na sua mais recente obra, Tiempo Nublado (1983), já se encarregou de nos lembrar que "a modernizaçáo sem democracia tecnifica as sociedades mas não as transforma". O pique transformador da modernidade é tanto maior quanto mais intenso for o impulso democrático. A Universidade, à medida que não consegue alargar o seu espaço democrático, seja em nível da gestão administrativa, seja em nível da instauraçáo do saber e essas duas vertentes se implicam ostensivamente -, registra uma espécie de recaída arcaizante, imobilista pela sua própria natureza. Como a USP responderia hoje a essa questáo formulada insistentemente pelos tempos modernos? Octavio Paz certamente diria: pelo nosso tempo nublado?

A modernidade cindida, na qual a pessoa humana e o seu contorno 
natural e social como que se desgarram para sempre, vem se revelando incompetente diante desse desafio que se avoluma. A modernização dependente, ou linearmente mimética, se equivoca redondamente quando supre que pode percorrer um caminho construtivo deixando de lado as suas obrigaçóes democráticas e democratizantes. É quando modernizar passa a ser sinônimo de tecnocratizar, e Michel Leiris se sente autorizado a falar em modernité-merdosité.

Em nenhuma época se moderniza se não se democratiza. $O$ índice precário de democratizaçáo expóe a insuficiência modernizadora da Universidade. E os seus habitantes, os professores, os alunos, os funcionários, experimentam uma incômoda sensação de que foram indexados como peças de museu. Talvez até tombados pela nossa política acanhadamente patrimonial.

A estrutura universitária vigente não quis, não soube, ou não pôde, ampliar a esfera de sua legitimidade. Permanece apegada a um formalismo anacrônico, impermeável socialmente. Desenraizado, portanto. Por isso a instituiçáo universitária deve procurar reerguer-se evitando, a uma só vez, o perigo corporativista e a tentaçáo anárquica. $O$ que somente será viável dilatando o seu horizonte intersubjetivo. É provável que venha a sair de dentro dela - desde que se reencontre criticamente com as suas raízes -, do interior de sua radicalidade democrática, alternativas modernizadoras genuínas. Caso contrário, ingressaremos na pós-modernidade - nós, os retardatários - , sem que tenhamos vivido, ou esgotado, a modernidade.

\section{O salto arriscado}

Todo salto traz consigo o risco do fracasso: jamais como intimidação, porém como repto. O salto é a razão de ser do saltador. As tarefas do conhecimento, que também se processam através de saltos, convivem com o risco sem o menor constrangimento. E pelo que vejo, os núcleos renovadores da USP - e eles existem em proporçóes reanimadoras, em meio a conhecidas dificuldades institucionais -, conduzem esse risco de modo criativo. Não quero dizer com isto que tudo são flores no percurso da USP. De maneira alguma. O próprio reencaminhamento do humanismo, um dos seus cavalos de batalha, continua submerso em prolongado impasse. O salto do humanismo transcendental para o novo bumanismo (ver revista Tempo Brasileiro no 73, 1983) não se consumou satisfatoriamente. Ou porque preservou as superstiçóes do humanismo filantrópico, ou porque denegou peremptoriamente o consciencialismo, em função de um cotejo sistêmico, supervalorizador da objetividade. As estratégias do humano afundam na vala comum das impug. 
naçóes epistemológicas. As visóes paleo ou neo positivistas, porque escamoteiam a realidade privilegiando ou arredondando fatos que são apenas fatias, alimentam uma idéia preconceituosa do fragmentário o náo-sistema que se confundiria, indevidamente, com o anti-sistema.

É fácil contudo perceber, entre os pesquisadores das ciências histórico-hermenêuticas (continuo falando daquela área da qual, suponho, me chegam informaçóes mais precisas), a superação da postura onisciente, ainda persistente da Universidade brasileira. Nesta hora se destaca a funçáo precípua da Universidade em épocas transitivas: manter vivo o saber e a vontade de saber - o saber por saber. Essa proposta nada teórica, descontínua e fragmentária, tem a vantagem de reconhecer a desproteçáo da Universidade no conjunto da vida do mundo. $\mathbf{E}$ evitar que se insista em pedir a ela o que ela não nos pode dar.

Com o esfacelamento da vida privada na cultura moderna, com a falência da particularidade, com o advento do homem sem atributos ou sem qualidades - para dizer com Robert Musil -, se oferecem como saídas alternativas, diferentes modalidades comunicativas, sem que os ganhos objetivos deixem de corresponder, necessariamente, a perdas simbólicas.

A democracia em curso, que não se resume no desempenho intelectual consagrado, terá de ser buscada dentro e fora dos campi. No campo aberto da sociedade civil. E provavelmente por intermédio de uma consciencia comunticativa. A pedagogia extramuros da USP parece apontar nesta direçáo.

\section{Aventura prospectiva}

Mesmo admitindo a aventura prospectiva como o desdobramento inevitável dessas anotaçóes, não será de todo improcedente pensar que o caminhar futuro da USP passa pelo seu passado. Criticamente. Essa prospecçáo consistiria em enfrentar o retorno às origens, olhando para a frente. Sem esquecer que toda Universidade constitui uma elaboraçáo cotidiana. A Universidade que se pressupóe de todo, que de todo é dada de antemáo, repete tão-somente as quimeras do transcendentalismo. $\mathrm{Da}$ mesma forma com que o conhecimento nunca precede aos materiais que se acham ao seu alcance, ou que podem ser por ele alcançados, no vaivem incessante que o identifica. Daí que o pluralismo crítico, jamais confundido com a heterodoxia teoricamente ingênua, se destaque como o seu combustível de todas as jornadas; força motriz de uma reflexáo talvez utopica, porém concretamente utópica, em nada semelhante às crenças abstratas dos nopos ricos do progresso: aqueles que se abandonaram ociosamente à fatalidade da evoluçáo. Os progressistas de agora năo pensam; confiam: piamente. 
A Universidade se debilita sempre que se afasta da teoria crítica da sociedade para, no seu lugar, entronizar os atos subseqüentes da razão opulenta, monotonamente idêntica a si mesma. Incapaz de compreender que os papéis habituais das figuras do conhecimento podem ser a qualquer momento remanejados, $\mathrm{e}$ as distâncias convencionais, entre a ficçáo e o saber científico, por exemplo, amanhecerão subvertidas.

E não há muito o que estranhar: é perfeitamente possível divisar, ainda próximas, as curvas da modernidade, que a USP acompanhou; nos seus mínimos movimentos.

Edısardo Portella é diretor geral adjunto da Organizaçăo das Naçôes Unidas para Educaçăo, Ciência e Cultura (Unesco) desde 1988. Foi ministro da Educaçăo e Cultura (1989-80) e professor da Universidade Federal do Rio de Janeiro. É autor, entre outros, de Retrato falado da educafto brasileira, O intelectual e o poder e Democracia transitiva.

Texto publicado no suplemento Folhetim, do jornal Folba de S. Paulo, de 22 janeiro de 1984. 


\section{AOS LEITORES}

Para transmitir aos leitores informafóes sobre a fase inicial e a evoluçá da Faculdade de Filosofia, Ciencias e Letras da Unipersidade de Sáo Paulo, foram colbidos depoimentos de alguns docentes que se formaram em suas primeiras turmas, em entrevistas dadas ao editor-executivo de Estudos Avançados, jornalista Marco Antdnio Coelho (na entrevista com o professor Marcelo Damy participou tambem o professor Alberto Luiz da Rocha Barros). Esses depoimentos, revistos pelos entrepistados, completam-se com as entredistas dos professores Crodowaldo Papan, Antonio Brito da Cunba e Erasmo Garcia Mendes - da antiga sefũo de Historia Natural (Biologia) -, publicadas no nuimero 18 de Estudos Avançados. Sobre Mário Schenberg, no numero 11, p. 195, encontra-se um artigo do professor Alberto L. da Rocha Barros. 